\title{
Effect of exercise training programme on bone mineral density in novice college rowers
}

\author{
B. Cohen, P. J. Millett, B. Mist*, M. A. Laskey ${ }^{\dagger}$ and N. Rushton \\ Orthopaedic Research Unit, Addenbrooke's Hospital, Cambridge, *Respiratory Physiology Department, \\ Papworth Hospital, Papworth Everard, and 'Department of Nuclear Medicine, Addenbrooke's Hospital, \\ Cambridge, UK
}

\begin{abstract}
Exercise has important effects on skeletal mineralization. Changes in bone mineral density (BMD) and bone mineral content (BMC) as measured by dual energy $X$-ray absorptiometry were investigated in a group of 17 male novice college oarsmen over a 7 -month period and were compared with eight age-matched controls. The rowing training programme consisted of approximately $8 \mathrm{~h}$ rowing, $1 \mathrm{~h}$ weight training, and $1 \mathrm{~h}$ running per week. After 7 months training the mean BMD of the lumbar spine (L1-L4) had increased significantly by $2.9 \%(P<0.001)$ and the mean BMC had increased by $4.2 \%(P<0.001)$. There was no significant change in the control group. Neither group showed a significant change in BMD or BMC in the femoral neck, greater trochanter or Ward's triangle. This study provides further evidence that exercise plays an important role in bone mineral formation.
\end{abstract}

Keywords: rowing, exercise, dual-energy $X$-ray absorptiometry, bone mineral density

Bone is a metabolically active tissue with continuous remodelling occurring throughout life. Although it has been noted for some time that athletes have a greater bone mineral density (BMD) than the normal population ${ }^{1,2}$, the role of exercise in bone mineralization is only recently being understood. The effects of exercise on BMD appear to be related to the mechanical stresses applied with maximal BMD in those regions of maximal stress ${ }^{2,3}$. For example, previous cross-sectional studies involving tennis players have demonstrated cortical hypertrophy and increased $\mathrm{BMD}$ in the playing arms $\mathrm{s}^{4,5}$. Others have shown increased BMD in the os calcis of runners ${ }^{6}$ and the lumbar spine of weightlifters ${ }^{7}$. There is also evidence that BMD is a function of muscle strength ${ }^{7-10}$. Snow-Harter et al. examined BMD in relation to muscle strength in young to middle-aged men and concluded that muscle strength did indeed make important contributions to $\mathrm{BMD}^{11}$. Doyle et al. demonstrated a significant correlation between the weight of the psoas muscle and the ash-weight of the third lumbar vertebral body in cadavers, thus indicating the close relationship that exists between

Address for correspondence: $\mathrm{Mr}$ B. Cohen FRCS, Orthopaedic Research Unit, Box 180, Addenbrooke's Hospital, Cambridge CB2 2QQ, UK functional loading and the adaptive response of bone?

Longitudinal studies in women have shown significant increases in BMD with exercise ${ }^{12}$. In an investigation involving pre-menopausal women, Gleeson et al. reported a significant difference in the percentage change of lumbar BMD in exercising women versus controls ${ }^{13}$. Many interventional exercise studies have demonstrated increased BMD in the lumbar spine $8,11-15$, femur ${ }^{8,11}$, tibia ${ }^{16}$, calcaneum ${ }^{6}$ and radius ${ }^{12,17}$; other studies however have not supported these findings ${ }^{18,19}$. A study by Smidt $e t$ al. found no difference in BMD of the lumbar spine or upper femur following 1 year of high intensity trunk exercise in postmenopausal women ${ }^{20}$. The extent of weight bearing seems to play a role although, in one recent non-weight bearing exercise study, Bloomfield et al. were still able to demonstrate an increase in bone mineral without the effects of gravity ${ }^{21}$.

Rowing is a sport which uses many of the large trunk muscles. Electromyographic studies of the muscle groups used during rowing have shown that maximum levels of activity occur in the sacrospinalis group during the end of drive phase of the rowing stroke $^{22}$. The thigh muscles also play an important role in the biomechanics of rowing, with the quadriceps contributing during the early and mid drive phases and the hamstrings contributing during the recovery phase ${ }^{22}$. As significant correlations have been found between spinal and femoral BMD and the isometric strength of back extensors ${ }^{10}$ and knee extensors $^{23}$, we decided to investigate whether rowing, a sport which uses these large muscle groups, could affect bone mineralization in these regions.

\section{Materials and methods}

The subjects recruited for this study were white healthy college age men from the University of Cambridge. Participation in the study was voluntary. To enhance compliance with the rigorous training programme the two groups were determined by personal choice rather than random assignment. The rowing group consisted of 17 highly motivated individuals from the men's novice rowing team. This group participated in a 7 month training programme consisting of approximately $8 \mathrm{~h}$ rowing per week, $1 \mathrm{~h}$ 
weight-training per week (emphasizing those muscles used in rowing), and $1 \mathrm{~h}$ running per week. The control group consisted of eight age-matched men. None of the subjects were reportedly taking any medication known to influence bone mineralization. Nutrition was not specifically controlled although all participants lived in college accommodations with similar dietary options. None of the subjects had previous rowing experience. No-one was restricted from participating in other forms of exercise, and all were encouraged to continue with their current lifestyle. Ethical permission and informed consent were obtained prior to the start of the study.

Dual-energy X-ray absorptiometry (DXA) is now widely used in clinical practice for the quantitative assessment of bone mineralization in metabolic bone disease $^{24,25}$. This technique has been shown to be a precise and accurate means by which BMD and BMC may be measured ${ }^{26-28}$. The primary areas studied with DXA are the femoral neck and lumbar spine. At the commencement of the study and 7 months later, $B M D$ and BMC of the lumbar spine (L1-L4), right femoral neck, greater trochanter, and Ward's triangle were measured in both groups using a Lunar DPX dual-energy X-ray absorptiometer (Lunar Radiation, Madison, Wisconsin, USA). The precision when measuring BMD in our hospital as published previously is $1.2 \%, 2.5 \%, 2.2 \%$ and $3.7 \%$ coefficient of variation for the spine (L2-L4), neck of femur, greater trochanter, and Ward's triangle respectively ${ }^{29}$. Quality controls were carried out daily according to manufacturer's instructions.

Demographic characteristics were analysed using unpaired Student's $t$ tests to compare descriptive data between groups. Paired Student's $t$ tests were used to analyse BMD and BMC within groups. One-way analysis of variance (ANOVA) was used to examine differences in BMD between the groups ${ }^{30}$.

\section{Results}

All 25 subjects completed the study. The demographic characteristics of the exercising and control groups at commencement of the study are listed in Table 1. There were no statistically significant differences between the groups in age, height, weight, BMD or BMC upon entry into the study. After 7 months there was no significant change in the mean body weight of the rowing group. The mean weight of the controls had increased by an average of $0.62 \mathrm{~kg}$ per person $(P<0.05)$. There was no statistically significant differences between the groups.

BMD and BMC results are summarized in Tables 2 and 3 respectively. At the end of the study, the mean(s.d.) lumbar BMD of the rowing group had increased significantly by $2.9 \%(2.0, P<0.001)$. While that of the control group had increased by $0.99 \%$, this was not found to be statistically significant. The BMD in the femoral neck, the greater trochanter, and Ward's triangle did not change significantly in either group.

The mean(s.d.) BMC in the lumbar spine of the exercising group increased significantly by $4.2 \%(2.9 \%, P<0.001)$ while there was a nonsignificant increase of $2.3 \%$ in the control group.
Table 1. Demographics of rowing and control groups

\begin{tabular}{lrr}
\hline & Rowers $(\mathrm{n}=17)$ & Controls $(\mathrm{n}=8)$ \\
\hline Age $(\mathrm{yr})$ & $19.5(2.4)$ & $19.3(1.6)$ \\
Height $(\mathrm{cm})$ & $182.8(5.7)$ & $180.3(9.4)$ \\
Weight $(\mathrm{kg})$ & $74.4(6.0)$ & $71.9(4.2)$ \\
\hline
\end{tabular}

All values are mean(s.d.)

Table 2. Bone mineral density (BMD) of lumbar spine and femur before and after 7 month rowing programme

\begin{tabular}{llll}
\hline & Before training & After training & $\%$ Change \\
\hline $\begin{array}{l}\text { Lumbar spine (L1-L4) } \\
\text { Rowers }\end{array}$ & $1.199(0.154)$ & $1.234(0.148)$ & $+2.90 \%(2.0)^{*}$ \\
$\quad$ Controls & $1.203(0.128)$ & $1.215(0.115)$ & $+0.99 \%(2.3)^{+}$ \\
$\begin{array}{l}\text { Femoral neck } \\
\text { Rowers }\end{array}$ & $1.18(0.172)$ & $1.179(0.176)$ & $-0.09 \%(3.3)^{+}$ \\
$\quad \begin{array}{l}\text { Controls } \\
\text { Greater trochanter }\end{array}$ & $1.20(0.142)$ & $1.209(0.123)$ & $+0.75 \%(2.8)^{+}$ \\
$\quad$ Rowers & $1.045(0.189)$ & $1.047(0.172)$ & $+0.19 \%(0.9)^{+}$ \\
$\quad$ Controls & $1.018(0.137)$ & $1.030(0.132)$ & $-1.20 \%(2.8)^{+}$ \\
$\begin{array}{l}\text { Ward's triangle } \\
\text { Rowers }\end{array}$ & $1.114(0.194)$ & $1.116(0.204)$ & $+1.75 \%(5.7)^{+}$ \\
Controls & $1.109(0.124)$ & $1.140(0.121)$ & $+3.10 \%(2.3)^{+}$ \\
\hline
\end{tabular}

All values are mean(s.d.) BMD in $\mathrm{g} / \mathrm{cm}^{2}(n=17$ for rowers; $n=8$ for controls); ${ }^{*} P<0.001 ;{ }^{+}$not significant

Table 3. Bone mineral content (BMC) of lumbar spine and femur before and after 7 month rowing programme

\begin{tabular}{lccc}
\hline & Before training & After training & \%Change \\
\hline $\begin{array}{l}\text { Lumbar spine }(L 1-L 4) \\
\text { Rowers }\end{array}$ & $77.5(15.2)$ & $82.86(15.23)$ & $+4.2 \%(2.9)^{*}$ \\
$\quad$ Controls & $76.61(10.25)$ & $78.42(9.29)$ & $+2.3 \%(3.0)^{+}$ \\
$\begin{array}{l}\text { Femoral neck } \\
\quad \text { Rowers }\end{array}$ & $6.55(1.16)$ & $6.58(1.21)$ & $+0.5 \%(3.4)^{+}$ \\
$\quad$ Controls & $6.25(0.38)$ & $6.36(0.72)$ & $+1.8 \%(1.8)^{+}$ \\
$\begin{array}{l}\text { Greater trochanter } \\
\text { Rowers }\end{array}$ & $15.46(3.68)$ & $15.88(3.56)$ & $+2.7 \%(6.9)^{+}$ \\
$\quad$ Controls & $15.94(3.57)$ & $16.23(3.41)$ & $-1.8 \%(5.5)^{+}$ \\
Ward's triangle & & & \\
$\quad$ Rowers & $3.77(0.97)$ & $3.89(1.11)$ & $+3.2 \%(6.3)^{+}$ \\
Controls & $3.36(0.49)$ & $3.53(0.59)$ & $+5.1 \%(3.8)^{+}$ \\
\hline
\end{tabular}

All values are mean(s.d.) BMC in grams ( $n=17$ for rowers; $n=8$ for controls); ${ }^{*} P<0.001 ;{ }^{+}$not significant

Again there was no significant change in the femoral neck, Ward's triangle, or greater trochanter in either group. There was no significant change in bone area in either group at any of the sites.

As determined by ANOVA, there were no statistically significant differences in lumbar or femoral BMD between the groups at any time during the study.

\section{Discussion}

The major mechanical stimuli for skeletal mineralization include muscle strain and gravity. It has been shown experimentally that strain is a stimulus for load-related bone remodelling and that there is an 
increasing osteogenic response to progressively increasing load ${ }^{31}$. The purpose of this study was to determine whether an intensive rowing training programme could elicit a similar osteogenic response in young male athletes. Our findings indicate that the BMD and the BMC of the lumbar spine did indeed increase over a relatively brief 7 month period of training. This supports the correlation found previously in a cross-sectional study by Wolman et al. in which they demonstrated increased spinal trabecular bone density in élite women rowers ${ }^{32}$. It is in contrast, however, to the results demonstrated by Smidt et al. ${ }^{20}$. We believe that the response seen in this study occurred because of the strain placed on the lumbar vertebrae by the sacrospinalis muscle group during the drive phase of the rowing stroke, although it is possible that weight-training and running also contributed.

It is somewhat surprising that this study detected no significant change in the femoral BMD with exercise as the muscles of the thigh contribute a major component of power during rowing. During the drive phase of the rowing stroke, the quadriceps muscle group contracts, while the hamstrings play an important role during the recovery phase. One explanation may be that the strain on the proximal femur during rowing may have been inadequate to elicit a significant osteogenic response. It is possible that rowing may not produce the same absolute forces through the hip joint as in other exercises. Cavanagh et al. have shown peak loads as measured under the feet to be over five times greater during running $\left(F_{\max } 1628.4 \mathrm{~N}\right)$ than during rowing $\left(\mathrm{F}_{\max }\right.$ $307.3 \mathrm{~N})^{33}$. In contrast with running, where loading is directly through the neck of the femur, when seated much of the gravitational force is displaced through the ischial tuberosities ${ }^{34}$. Thus, during the drive phase of the rowing stroke, maximal force on the proximal femur is exerted almost exclusively by muscle activity without gravitational contributions, and as such may not exceed the threshold necessary to cause a significant osteogenic response.

It has also been shown previously that cortical bone has a relatively slower metabolic response to stress than trabecular bone $e^{20,35}$, and as such it is certainly plausible that while the duration of the study allowed us to measure trabecular changes in the spine it prevented us from detecting slower cortical adaptations in the femur. Ideally, there would have been a longer period of follow-up, but this was limited somewhat by the relatively short novice rowing season. It has been shown that skeletal response to applied load may be greater in younger than in older individuals $^{12,36,37}$, which may help to explain why we found a significant change in BMD and BMC during the relatively brief training period.

A third explanation for the lack of a significant femoral response may be the relatively lower precision of dual-energy $X$-ray absorptiometer in measuring BMD in this region. As the Lunar DPX is two to three times less precise in the proximal femur, it may have failed to detect subtle changes in femoral $\mathrm{BMD}^{29}$.

We believe that it is unlikely that other factors known to be important in skeletal mineralization, such as genetics and nutrition, played a significant role in this study. With regard to genetics for instance, the two groups were rather homogeneous, and there was no significant difference between groups in BMD or BMC at the start of the study. As there is evidence that diet, particularly dietary calcium, can influence bone mineralization ${ }^{38,39}$, ideally the nutritional intake in the two groups would have been identical. Although all the subjects had similar dietary options, it is possible that their actual nutritional intake differed. We believe however that it is unlikely that these two factors played major roles in this study as we found a localized increase only in the lumbar spine, the area of maximal mechanical stress, without significant changes in the femur. If there has been some genetic or nutritional effect we believe this would have been reflected by changes in the femur as well. Moreover, it is unlikely that body weight played a significant role as the weight of the exercising group did not change significantly while that of the control group increased slightly. As increased weight is generally correlated with increased skeletal mass ${ }^{40}$, we would have expected to find increased bone mineral in the control group.

The types of exercise that maximize bone formation are yet to be determined. In theory, the regimen is likely to be one that exposes the skeleton to high strains at high strain-rates in a variety of distributions ${ }^{41}$. The results of this study support the theory that exercise is a significant stimulus for osteogenesis and give further evidence that mineralization is related to mechanical loading. Further research is certainly merited so that we may gain a better understanding of the exact mechanism by which exercise stimulates bone formation as well as which form promotes optimum mineralization.

\section{Acknowledgements}

The authors wish to thank Addenbrooke's Hospital Trust Fund for support of this project.

\section{References}

1 Dalen $\mathrm{N}$, Olsen KE. Bone mineral content and physical activity. Acta Orthop Scand 1974; 45: 170-4

2 Nilsson BE, Westlin NE. Bone density in athletes. Clin Orth 1971; 77: 179-82.

3 Granhed $H$, Jonson R, Hansson T. The loads of the lumbar spine during extreme weight lifting. Spine 1987; 12: 146-9.

4 Huddleston AL, Rockwell D, Kulund DN, Harrison RB. Bone mass in lifetime tennis athletes. JAMA 1980; 244: 1107-9.

5 Jones $\mathrm{HH}$, Priest JD, Hayes WC, Tichenor CC, Nagel DA. Humeral hypertrophy in response to exercise. J Bone Joint Surg 1977; 59A: 204-8.

6 Williams JA, Wagner J, Wasnich R. The effect of long distance running upon appendicular bone mineral content. Med Sci Sports Exerc 1984; 16: 223-7.

7 Doyle F, Brown J, La Chance. Relation between bone mass and muscle weight. Lancet 1970; 1: 391-3.

8 Colletti LA, Edwards J, Gordon L, Shary J, Bell NH. The effects of muscle-building exercise on bone mineral density of the radius, spine, and hip in young men. Calcif Tiss Int 1989; 45: 12-14.

9 Pocock N, Eisman J, Gwinn T et al. Muscle strength, physical fitness and weight but not age predict femoral neck bone mass. J Bone Min Res 1989; 4: 441-7.

10 Sinaki M, McPhee MC, Hodgson SF, Merritt JM, Offord KP. Relationship between bone mineral density of the spine and strength of the back extensors in healthy postmenopausal women. Mayo Clin Proc 1986; 61: 116-22. 
11 Snow-Harter C, Whalen R, Myburgh K, Arnaud S, Marcus R. Bone mineral density, muscle strength, and recreational exercise in men. J Bon Min Res 1992; 7: 1291-6.

12 Chow R, Harrison JE, Notarius C. Effect of two randomised exercise programmes on bone mass of healthy postmenopausal women. $\mathrm{Br}$ Med J 1987; 295: 1441-4.

13 Gleeson PB, Protas EJ, LeBlanc AD, Schneider VS, Evans HJ. Effects of weight lifting on bone mineral density in premenopausal women. I Bone Min Res 1990; 5: 153-8.

14 Dalsky GP, Stocke KS, Ehsani AA. Weight bearing exercise training and lumbar bone mineral content in post-menopausal women. Ann Intern Med 1988; 108: 824-8.

15 Krolner B, Toft B, Nielson SP, Tondevold E. Physical exercise as a prophylaxis against involutional vertebral bone loss: a controlled trial. Clin Sci 1983; 64: 541-6.

16 Margulies JY, Simkin A, Leichter I et al. Effect of intense physical activity on the bone mineral content in the lower limbs of young adults. J Bone Joint Surg 1986; 68A: 1090-3.

17 Beverly MC, Rider TA, Evans MJ, Smith R. Local bone mineral response to brief exercise that stresses the skeleton. $\mathrm{Br}$ Med J 1989; 299: 233-5.

18 Cavanaugh DJ, Cann CE. Brisk walking does not stop bone loss in postmenopausal women. Bone 1988; 9: 201-4.

19 Rockwell JC, Sorenson AM, Stock J, Michaels J, Baran DT. Weight training does not increase bone mass in premenopausal women. J Bon Min Res 1989; 4(Suppl): 188.

20 Smidt GL, Lin SY, O'Dwyer MA, Blanpied PR. The effect of high-intensity trunk exercise on bone mineral density of postmenopausal women. Spine 1992; 17: 280-5.

21 Bloomfield SA, Williams NI, Lamb DR, Jackson RD. Non-weight bearing exercise may increase lumbar spine bone mineral density in healthy postmenopausal women. $\mathrm{Am} \mathrm{J}$ Phys Med Rehab 1993; 72: 204-9.

22 Rodriguez RJ, Rodriguez RP, Cook SD, Sandborn PM. Electromyographic analysis of rowing stroke biomechanics. J Sports Med Phys Fitness 1990; 30: 103-8.

23 Pocock NA, Eisman JA, Yeates MG, Sambrook PN, Eberl S. Physical fitness is a major determinant of femoral neck and lumbar spine bone mineral density. J Clin Invest 1986; 78: 618-21.

24 Pacifici R, Rupich R, Griffin NC, Hines A, Susman N, Aviolli LV. Dual energy radiography versus quantitative computer tomography for the diagnosis of osteoporosis. J Clin Endocrinol Metab 1990; 70: 705-10.

25 Sartoris DJ, Resnik D. Current and innovative methods for non-invasive bone densitometry. Radiol Clin North Am 1990; 28: 257-78.

26 Kelly TL, Slovick DM, Schoenfield DA, Neer RM. Quantita- tive digital radiography versus dual photon absorptiometry of the lumbar spine. J Clin Endocrinol Metab 1988; 67: 839-44.

27 Lilley J, Walters BG, Heath DA, Drole Z. In vivo and in vitro precision for bone density measured by dual energy $X$-ray absorption. Osteoporosis Int 1991; 1: 141-6.

28 Mazess R, Collick B, Trempe J, Barden H, Hanson J. Performance evaluation of a dual-energy $X$-ray bone densitometer. Calcif Tissue Int 1989; 44: 228-32.

29 Laskey MA, Flaxman ME, Barber RW, et al. Comparative performance in vitro and in vivo of Lunar DPX and Hologic QDR-1000 dual-energy X-ray absorptiometers. $\mathrm{Br} J$ Radiol 1991; 64:1023-9.

30 Zolman JF. Biostatistics: Experimental Design and Statistical Inference. Oxford, UK: Oxford University Press. 1993; 158-69.

31 Rubin CT, Lanyon LE. Regulation of bone formation by applied dynamic loads. J Bone Joint Surg 1984; 66A: 397-402.

32 Wolman RL, Clark $P$, McNally E, Harries $M$, Reeve J. Menstrual state and exercise as determinants of spinal trabecular bone density in female athletes. $\mathrm{Br}$ Med J 1990; 301: 516-8.

33 Cavanagh PR, Davis BL, Miller TA. A biomechanical perspective on exercise countermeasures for long term space flight. Aviation, Space and Environmental Medicine 1992; 63: 482-5.

34 Williams JGP, Scott AC eds. Rowing: A scientific approach. London, UK: Kaye and Ward Ltd. 1967; 81-109.

35 Laan RFJM, van Riel PLCM, van de Putte LVB, van Erning LJTO, van't Hof MA, Lemmens JAM. Low-dose prednisone induces rapid reversible axial bone loss in patients with rheumatoid arthritis. Ann Int Med 1993; 119: 963-8.

36 Block JE, Smith R. Overview of exercise and bone mass. In: Genant HK, ed. Osteoporosis Update 1987. San Francisco USA: Radiology, Research and Education Foundation. 267-70.

37 Kelsey JL. Osteoporosis: Prevalence and incidence. National Institute of Health Consensus Development Conference, Bethesda MD, USA, 1984

38 Lloyd T, Andon MB, Rollings RN, Martel JK, Landis JR, Demers LM, Eggli DF, Kiesselhorst K, Kulin K. Calcium supplementation and bone mineral density in adolescent girls. JAMA 1993; 270: 841-4.

39 Nelson ME, Fisher EC, Dilmanian FA, Dallal GE, Evans WJ. A 1-y walking program and increased dietary calcium in postmenopausal women: effects on bone. Am J Clin Nut 1991; 53: 1304-11.

40 Saville PD, Nilsson BER. Height and weight in symptomatic postmenopausal osteoporosis. Clin Orthop 1966; 45: 49.

41 Lanyon LE. The physiological basis of training the skeleton. Equine Vet J 1990; 9S: 8-13. 